\title{
A Process-based Classification of Knowledge Maps and Select Application Examples
}

Martin J. Eppler, $\mathrm{PhD}$

Chair of Information and Communication Management

University of Lugano (USI), Via Buffi 10, 6900 Lugano, Switzerland

Martin.Eppler@lu.unisi.ch

Acknowledgements: Funding for this research has been provided by the Tasso Foundation.

\begin{abstract}
This article discusses pragmatic ways of classifying knowledge maps to give an overview of their application contexts and formats. In the article, we show where and how the term knowledge map has been previously used and what criteria must be met in a sound and useful knowledge map classification that can support knowledge management processes. Various classification principles are presented and discussed. A table then matches map formats to knowledge management purposes and knowledgerelated contents in order to serve as a selection and organizing framework. Examples of some of the main types of knowledge maps are presented to illustrate the varieties of knowledge mapping present in the classification. The article concludes by discussing its limitations and future research questions in the area of knowledge mapping.
\end{abstract}




\section{A PROCESS-BASED CLASSIFICATION OF KNOWLEDGE MAPS AND APPLICATION EXAMPLES}

\section{INTRODUCTION}

An early step toward understanding any set of phenomena is to learn what kinds of things there are in the set-to develop a taxonomy. HERBERT A. SIMON

The advantages of visual representations for the field of knowledge management have long been recognized and discussed (Newbern and Dansereau, 1995, Sparrow, 1998, Vail, 1999, Wurman, 2001, Wexler, 2001, Eppler, 2002, Eppler, 2003) and include a better overview, a faster access and a more efficient and memorable representation and communication of knowledge assets (such as experts, practice documents, communities, patents, etc.). Visual representations have also proved particularly useful in eliciting Hodgkinson et al., 2004) or referencing implicit knowledge (Sparrow, 1998, Meyer, 1991) and thus can help to make knowledge more widely and easily available. The terms knowledge map (Sparrow, 1998, Eppler, 2002) or knowledge mapping (Wexler, 2001) have been used to designate a wide variety of approaches to organize and structure knowledge sources, knowledge application steps, insightful concepts, expert networks or communities of practice (Vail, 1999). These varieties of knowledge maps have so far never been systematically classified and compared in terms of their characteristics, unique features or application parameters (for a first tentative classification see Eppler, 2002). 
There are numerous benefits that can be achieved through a classification of knowledge maps: First, it can provide a descriptive overview of the domain (Bailey, 1994, p.12) and can function as an inventory or repository (ibid., p.13) like a structured toolbox. In this way a classification can also become a problem solving heuristic (Dherbey, 2005, p. 68) that relates possible mapping solutions to knowledge management challenges. Thus, a classification reduces the complexity inherent in choosing a knowledge map format for a particular application context. As a further benefit, a map classification helps to recognize the similarities and differences among different types of knowledge maps. It helps to compare different types of knowledge maps along pertinent criteria. As a side-benefit of developing a classification, one has to develop an exhaustive description of the variables that define a knowledge map's application context. Finally, a classification of knowledge maps may also reveal new forms of knowledge maps that so far have not been applied. The classification may systematically go beyond the current state-of-the-art practice of knowledge mapping and show potential future formats. Having listed the benefits that can be expected from a systematic classification of knowledge maps, one should also note the potential disadvantages of this research approach. Such disadvantages are the focus on description, rather than explanation. Classification may lead to reification (Bailey, 1994, p. 15), that is to say to pretending that an ideal archetype does exist, when it's merely hypothetical. Tied to this criticism is the fact - relevant in many knowledge management application contexts - that classifications tend to be rather static and difficult to adjust as a domain changes and evolves.

These disadvantages lead to the recommendation that a classification system should not just rely on one classification principle, but should propose various, alternative 
classification criteria. In section four of this article we will thus propose different useful classification principles to structure the domain of knowledge mapping.

\section{REQUIREMENTS OF A CLASSIFICATION SYSTEM}

Classification lies at the heart of every scientific field. Classifications structure domains of systematic inquiry and provide concepts for developing theories to identify anomalies and to predict future research needs.

\section{LOHSE ET AL., 1994}

Before examining existing classifications of knowledge maps (in section three) and proposing our own set of categories (in section four), we should briefly examine the general rules or criteria that lead to valid and useful classifications. In this section we thus review the key requirements discussed in classification and categorization literature (Bailey, 1994, Bowker and Star, 1999, Dherbey, 2005, Minto, 1995, Wurman, 2001, Lakoff, 1987) in order to apply this research method adequately. A classification, according to Bailey (1994) is the ordering of entities into groups or classes on the basis of their similarity. Classifications minimize within-group variance, and maximize between-group variance (Bowker and Star, 1999). In other words, a classification should maximize the homogeneity within a group, as well as the heterogeneity among groups, thus facilitating analysis, organization and assessment (Bailey, 1994). Classification (according to Bowker and Star, 1999) can also be described as a spatialtemporal segmentation of the world (or one aspect of it). Taxonomies, as a special kind of classification, are tied to a purpose, in the context of this paper allocating the right type of knowledge map to the right type of knowledge management problem. Bailey 
points out the difference between taxonomy and typology: Whereas a typology is conceptual, deductive and based on reasoning, a taxonomy is empirical, inductive, and based on large sets that are examined and grouped (Bailey, 1994, p. v). The classification proposed in this paper is partly a taxonomy derived from existing real life knowledge maps. In part, it is a typology, as it aims to point out other possible forms of knowledge mapping that may not yet have been applied in real-life contexts. A highquality classification system that is fit for use should be both consistent and manageable. Consequently it should meet at least two sets of criteria, namely logic criteria and pragmatic criteria. In terms of the logic or formal criteria that make a classification sound, the classification has to have unique classificatory principles in operation which are not mixed at each level of abstraction or hierarchy (Minto, 1995, Wurman 2001, Bailey, 1994). This will ideally guarantee that the resulting categories are mutually exclusive (non-overlapping) (Minto, 1995), and that the classification system is complete (the categories are collectively exhaustive), meaning that there are no items in the domain that cannot be assigned to a category (the classification is comprehensive). A classification should capture the totality of phenomena supposedly contained within it. In our case, there shouldn't be knowledge maps that cannot be classified within the proposed system. Furthermore, a good classification assigns items to groups based on objective and stable attributes, so that there are no unclear category fits of particular items. The labels for different groups (on a particular hierarchic level) are on the same level of abstraction (ibid.); the classification should not mix specific (sub-) groups with very general ones. It should also be made explicit what lies beyond the categorization scope: the boundaries of the classified domain or area should be clear (i.e., one should give inclusion or exclusion criteria). With regard to the pragmatic 
criteria that make a classification more ergonomic to use, one must pay attention to self-explanatory informative category names, as well as take into account the total number of categories that should not result in an overly heavy cognitive load for the targeted users. The process of item attribution to a category is made easier, if each category has a typical representative, a so-called prototype member that can act as a mnemonic device for the category and thus makes it more memorable (Lakoff, 1987). The granularity of the classification should be in line with its intended use requirements (not more specific than actually needed). In summary, we can state that an ideal (sound and useful) classification should have the following properties, of which the first six are formal (or soundness) criteria and the subsequent four are pragmatic (or usability) ones:

1. It consists of mutually exclusive categories (groups that do not overlap),

2. that are collectively exhaustive (i.e., together the groups cover the entire classified domain),

3. that are based on stable and objective grouping criteria (in order to unequivocally assign an item to a category in a classification),

4. that have category names on a consistent level of abstraction (per hierarchic level),

5. based on one explicit, consistent and informative classification principle per level of hierarchy,

6. for a clearly specified and delineated topic area or domain,

7. where the categories have self-explanatory, informative category names or labels,

8. and contain typical, representative (prototype) members for each group in the classification, 
9. resulting in a well-organized system that does not overload the users as it contains an adequate amount of groups that can still be managed by short term memory (the granularity of the distinction does not exceed the level of detail necessary for the envisioned task that the classification supports),

10. a system that is hence understandable and usable by the envisioned user groups.

The ten criteria compiled above can provide guidelines for the assessment of current knowledge map classifications and for the development of new classifications. The former is presented in the next section, the latter in the subsequent section.

\section{PRIOR DEFINITIONS AND TYPOLOGIES OF KNOWLEDGE MAPS}

The map is the territory if people treat it as such.

KARL WEICK

In this section, we review prior definitions and classifications of knowledge maps and point out their limitations and the resulting need for new classifications. The term knowledge map has so far been used in at least seven different scientific communities: in education studies or in researching instructional methods, such as mind maps, concept maps and related graphic learning tools (Tergan \& Keller, 2005), in organization studies (Huff and Jenkins, 2002, Huff, 1999) and in requirements engineering (Browne and Ramesh, 2002) where the term designates the elicited, visualized mental models of managers or IT users, in decision analysis to elicit crucial information (Bowne et al., 1997) in information retrieval to designate interactive search 
result displays and search result browsing interfaces (Coyne, 1995), in decision support systems to designate, among other things, the informative graphic rendering of decision variables (Smelcer and Carmel, 1997) in artificial intelligence where it can designate the conceptual representation of an expert domain (Gordon, 2000), and in the knowledge management community (Vail, 1999, Burnett et al., 2004). In the context of knowledge management, a knowledge map generally designates an overview on a collection of knowledge related contents. A knowledge map typically consists of two main parts: a ground or background layer which represents the context for the mapping, and the individual elements that are mapped within this context. The elements which are mapped onto such a shared context range from experts, project teams, or communities of practice to more explicit and codified forms of knowledge such as white papers or articles, patents, lessons learned (e.g., after action reviews or project debriefings), events (i.e., trainings), databases or similar IT applications, such as expert systems or simulations. Knowledge maps group these elements to show their relationships, locations, or other attributes. Knowledge maps answer questions such as: how do I find relevant knowledge, how can I judge its quality, how can I make sense of its structure, and how do I go about applying or developing it? Definitions of knowledge maps that we have found in the literature follow this logic. Vail, for example, defines a knowledge map as follows (Vail, 1999, p. 10):

\footnotetext{
„A knowledge map is a visual display of captured information and relationships, which enables the efficient communication and learning of knowledge by observers with differing backgrounds at multiple levels of detail. The individual items of knowledge included in such a map can be text, stories, graphics, models,
} 
or numbers. [...] „Knowledge mapping is defined as the process of associating items of information or knowledge (preferably visually) in such a way that the mapping itself also creates additional knowledge."

A more recent definition by Renukappa and Egbu (2004) also stresses relationships, but adds the important element of maps referring also to tacit knowledge. It also highlights the important notion of knowledge dynamics, next to knowledge stores or repositories:

"A knowledge map is a navigation aid to both explicit and tacit knowledge, showing the importance and the relationships between knowledge 'stores' and the dynamics"

According to Ernst \& Young (Novins, 1997), to take a practitioner's definition, a knowledge map is a place to find the source of answers, a method and format for collecting and communicating where knowledge resides and is lacking, typically within an organization, a visual representation of the knowledge content areas. Based on these typical definitions we can conclude that the minimal criteria for a knowledge map are that it is a graphic overview and reference of knowledge-related content that serves a knowledge management related purpose.

Let us next look at how this domain has been structured so far, that is to say which types of knowledge maps have already been distinguished. In knowledge management, the classical cartographic map types (aimed at representing information about a 
geographic territory) are less fruitful (see Peterson, 1995). Eppler (2002) proposes a simple knowledge map typology based on knowledge management tasks, namely knowledge creation and development maps, knowledge identification maps, knowledge assessment maps, and knowledge application maps. The main problem with this classification is that it is not comprehensive, versatile or precise enough to be of general use in knowledge management.

A different, more abstract set of map categories is used by Anne S. Huff in her anthologies on the topic of mapping strategic thought and knowledge (Huff and Jenkins, 2002, Huff, 1999). In her mapping typology, she focuses on cognitive maps and distinguishes the following map types: text and language analysis maps, classification maps, network maps, conclusive maps, and schematic maps of cognitive structures (Huff and Jenkins, 2002). The problem with this classification is that it is not based on one consistent classification principle and not always applicable to knowledge management.

Novins (1997) distinguishes among three types of knowledge maps, namely pointer models (pointing to the correct source, usually a person), linkage models (adding some meta information on the sources), and solution models (relating knowledge areas to business problems). Pointer models are knowledge source maps that typically map experts. They can be geographic or organized by topic. Linkage models provide more visual context on how the referenced knowledge can be used, for example by linking knowledge to a visualized business process. Still more meta-information on the referenced knowledge is represented in solution models. In this type of dense and informative map descriptive and prescriptive elements are mixed. While this is a useful 
categorization, its groups are not fully mutually exclusive and the classification only focuses on the main functions and content types of knowledge maps and neglects other application parameters such as graphic format, scope, medium, creation mode, or required skill level.

These existing classifications and distinctions are relevant, but they may be limiting the potential of knowledge maps to too few areas. It may be beneficial to explore new, alternative and concurrent ways of classifying knowledge maps in order to explore and extend their application potential beyond the currently implemented or envisioned solutions. Developing multiple classification schemes may also improve our understanding of the application parameters of different forms of knowledge maps. Such new classifications - that strive to meet the ten categorization criteria listed previously - are explored in the next section

\section{CLASSIFICATION PRINCIPLES AND TYPOLOGIES FOR KNOWLEDGE MAPS}

You do not understand anything, until you understand it in more than one way.

\section{MARVIN MINSKY}

In the study of taxonomies, there is a general rule that a classification should always be based on key characteristics of its items, but - according to Bailey - there is no proven rule to find these attributes (Bailey, 1994, p. 2). Nevertheless, cognitive linguist George Lakoff provides insightful directions in his theory of categorization. A classification according to Lakoff (1998) can be one of four types. These types are: 
1. Purposive: categorizing by intended use: in our context classifying maps by the knowledge management purpose they serve.

2. Perceptual: categorizing by common format/look: in our case, by the graphic format of a knowledge map.

3. Functional: categorizing by personal use or type of the content of the knowledge map.

4. Motor-activity: based on physical interaction with the content: in our case the medium or application context of a knowledge map.

These classification principles can also be found in seminal taxonomies of visual representations: Shneiderman's task by type taxonomy of visual representation formats (Shneiderman, 1996) suggests both application purpose or functionality (task) and content (type) as classification principles. Lohse et al. (1994) conclude that extant taxonomies of graphs and images in general are either functional, i.e., by purpose, or structural, i.e., by graphic form, although there are also model-based taxonomies (Chi, 2000, Tory and Möller, 2002), as well as other possible classification criteria, such as social context, or cognitive process, see (Blackwell and Engelhardt, 2002). An example of a functional taxonomy has been developed by Tufte (1990), structural classifications have been developed by Bertin (1994), Horn (1999) and Rankin (1990). From these prior approaches we derive our primary knowledge map classification principles, which are by purpose, by graphic form, by content, by application level, and by creation mode. We believe that these classification principles are relevant for a pragmatic taxonomy of knowledge maps as they all relate to the actual application of knowledge maps. The pragmatic logic of these classification principles can be illustrated (see also 
Wexler, 2001) by converting them into questions or interrogatives: Choosing a particular type of knowledge map necessitates answering a number of key questions, namely:

1. Which knowledge management purpose do I want to achieve with the map? (the 'why?' of the map)

2. Which kind of content about knowledge do I want to represent in the map? (the 'what?' of the map)

3. Who should use the map in which context or situation and at what level (the 'for whom?' and 'when?' of the map)

4. Which graphic form should be used and who can create the map in what way? (the 'how?' and 'who?' of the map)

While the purpose describes the knowledge management task supported by the map (frequently tied to an application context), the content dimension describes the elements that are contained and referenced in a knowledge map. Usually, a knowledge map contains only one kind of content, although there are maps that contain information on experts, documents, communities, and databases in parallel. The following table 1 shows sample knowledge map types based on these primary classification principles. The items in the open lists are intended to serve as illustrative examples and not as exhaustive options.

Table 1. Knowledge map classifications

A. Classifying knowledge maps by intended purpose or KM process ('why?'):

1. knowledge creation maps: illustrate the planned steps to develop a certain (organizational) competence or create new knowledge (i.e., a technology road map)

2. knowledge assessment or audit maps: illustrate the evaluation of certain knowledge assets graphically for example by a $2 \times 2$ matrix (axes: current ability and future importance) 
3. knowledge identification maps: provide a graphic overview on knowledge assets (experts, patents, practices) and points to their locations / coordinates

4. knowledge development or acquisition maps / learning maps:

a) Learning overview and learning path maps

b) Learning content structure maps

c) Learning reviewing / repetition maps

5. knowledge transfer, sharing or communication maps: show who transfers knowledge to whom

6. knowledge application maps: show which knowledge is necessary for carrying out certain processes or steps in a single process.

7. knowledge marketing maps: can be used to signal competence to the public in a certain domain.

B. Classifying maps by their content ('what?'):

I. by (digital and analogue) content formats: 1. websites (incl. blogs, portals, homepages), 2. documents (incl. books), 3. databases or repositories, 4. learning objects or online courses (or modules) 4. other file formats (e.g., sketches, drawings).

II. by content types: 1. methods, 2. processes, 3. experts (incl. groups), 4. organizations/departments/institutions, 5. lessons learned/experiences, 6. skills \& competencies 7. concepts, 8. events, 9. patents 10. knowledge or communication flows or relationships 11. interests or knowledge needs

C. Classifying maps by the application level ('who?'):

1. personal knowledge maps (visualizing one's own skills or expert contacts, see (Eppler and Sukowski, 2000) or Burnett et al., 2004)

2. dyadic knowledge map (to support knowledge creation, transfer or assessment between two people)

3. team knowledge maps (visualize the skills present or needed in a project team, like the T-matrix, see Eppler and Sukowski, 2000)

4. departmental knowledge maps

5. community knowledge maps

6. organizational knowledge maps

7. inter-organizational / network knowledge maps

D. Classifying knowledge maps by graphic form ('how?'):

I Table-based format (for an example see Heng, 2001):

1. person by skills table

2. skill area by people table

3. people by documents

4. team by project experience table

II. Diagrammatic format:

1. Structure diagrams

a) Venn diagram b) Concentric circles (with or without segments) c) Matrix (i.e., 2 by 2) d) Network diagram e) Mind Map f) Concept Map (Tergan \& Keller, 2005) g) Cognitive Map (Huff and Jenkins, 2002) h) Strategy Map i) Fishbone

2. Process diagrams (Galloway, 1994)

a) Timeline b) Swim lane chart c) Flow chart d) Event chain e) Critical path method f) Gantt chart

g) Cycle chart h) Decision Tree i) Value chain j) Flight plan (Eppler and Sukowski, 2000)

III Cartographic format:

1. geographic map: globe / continent / land / island / region 2. informational map: park 3. tube / metro (Burkhard and Meier, 2005) map 4. galaxy / stars 5. sea / ocean 6. building / architectural map

IV. Metaphoric format:

a) from the natural realm: 1 . tree 2. iceberg 3. canyon 4. mountain 5. river $6 \ldots$

b) man made artifacts: $\quad 1$. house 2 . temple structure 3 . radar screen 4 . bridge 5 . race track $6 \ldots$

E. Classifying maps by their creation method ('how?' and 'who?') 
1. maps that are automatically and dynamically generated by the computer (such as self-organizing maps, see Kohonen 2001),

2. maps that are semi-automatically generated (automatically assembled and then optimized by analysts)

3. maps that are designed once by domain and mapping experts and then used in the same way by all users.

4. maps that are iteratively created, modified, or extended by the map user(s) themselves (community generated maps)

Other possible, but potentially less useful, stable or objective classification principles include the managerial application domain or functional area (e.g., maps for project management, strategy, quality management, procurement, risk management, finance, production, etc.) the amount of resources (time, money) associated with generating, updating or using a map, the required skill level of map users (from novice maps to expert maps), the size of the map (10 entries versus 10'000 entries), and the medium of the map (paper, poster, or digital).

Having presented different possible classification principles and resulting typologies, we can now combine the most relevant ones into a matching matrix that can serve as a first, generic selection guide for knowledge maps (that evidently requires adaptation for specific application contexts). For this matrix, we chose the use of the knowledge map in knowledge management (the knowledge management process) as the dominant feature, as well as the format of the map and the level and content type of the map (the former two as table axes, the later two as table entries). These are considered to be the most relevant dimensions as they guide the actual implementation process: Knowledge content needs to be adequately represented in a graphic format for a particular knowledge management process at a certain level. In this sense, the following matrix can serve as a starting point and discussion template for a deliberation on which 
kind of knowledge map may be useful for a given knowledge management process or challenge.

Table 2: A possible matching matrix for knowledge map parameters

\begin{tabular}{|c|c|c|c|c|}
\hline $\begin{array}{l}\text { K Map Format / } \\
\text { Knowledge Management } \\
\text { Process / Purpose: }\end{array}$ & $\begin{array}{l}\text { I Table } \\
\text { Format }\end{array}$ & $\begin{array}{l}\text { II Diagrammatic } \\
\text { Format }\end{array}$ & $\begin{array}{l}\text { III Cartographic } \\
\text { Format }\end{array}$ & $\begin{array}{l}\text { IV Metaphoric } \\
\text { Format }\end{array}$ \\
\hline $\begin{array}{l}\text { 1. Creation of } \\
\text { Knowledge }\end{array}$ & & $\begin{array}{l}\text { M,L,C } \\
1-3\end{array}$ & $\begin{array}{l}\text { M,L,C } \\
1-3\end{array}$ & $\begin{array}{l}\text { M,L,C } \\
1-3\end{array}$ \\
\hline $\begin{array}{l}\text { 2. Assessment or Audit } \\
\text { of Knowledge }\end{array}$ & $\begin{array}{l}\text { E, F, S } \\
1-5\end{array}$ & $\begin{array}{l}E, F, S \\
1-5\end{array}$ & & \\
\hline $\begin{array}{l}\text { 3. Identification of } \\
\text { Knowledge }\end{array}$ & $\begin{array}{l}\text { M, E } \\
1-4\end{array}$ & $\begin{array}{l}\text { M,E, F } \\
1-7\end{array}$ & $\begin{array}{l}\text { M,E, F } \\
1-7\end{array}$ & $\begin{array}{l}\text { M,E,F } \\
1-7\end{array}$ \\
\hline $\begin{array}{l}\text { 4. Development of } \\
\text { Knowledge }\end{array}$ & & $\begin{array}{l}\text { M,S, C } \\
1-7\end{array}$ & $\begin{array}{l}\text { M, S, C } \\
1-7\end{array}$ & $\begin{array}{l}\text { M,S, C } \\
1-7\end{array}$ \\
\hline $\begin{array}{l}\text { 5. Sharing, } \\
\text { Transferring, } \\
\text { Communication of } \\
\text { Knowledge }\end{array}$ & $\begin{array}{l}M \\
2-7\end{array}$ & $\begin{array}{l}\text { M, L, C, S, F } \\
2-7\end{array}$ & $\begin{array}{l}\text { M, L, C, S } \\
2-7\end{array}$ & $\begin{array}{l}\text { M, L, C, S } \\
2-7\end{array}$ \\
\hline $\begin{array}{l}\text { 6. Application of } \\
\text { Knowledge }\end{array}$ & $\begin{array}{l}\text { M, L, S } \\
1-7\end{array}$ & $\begin{array}{l}\text { M, L, S } \\
1-7\end{array}$ & $\begin{array}{l}\text { M, L, S } \\
1-7\end{array}$ & $\begin{array}{l}\text { M, L, S } \\
1-7\end{array}$ \\
\hline $\begin{array}{l}\text { 7. Marketing of } \\
\text { Knowledge }\end{array}$ & & $\begin{array}{l}\text { M, E, C, S } \\
4-7\end{array}$ & $\begin{array}{l}\text { M, E, C, S } \\
4-7\end{array}$ & $\begin{array}{l}\text { M, E, C, S } \\
4-7\end{array}$ \\
\hline
\end{tabular}

\section{Knowledge Map Content Types:}

$\mathrm{M}=$ methods (procedural knowledge, know-how)

$\mathrm{E}=$ experts, organizations, groups, institutions etc. (know-who, knowledge carriers)

$\mathrm{L}=$ lessons learned, and experiences (know-why)

$\mathrm{C}=$ concepts (declarative knowledge, know-what)

$\mathrm{F}=$ flows or relationships (i.e., communication flows, collaboration relations)

$\mathrm{S}=$ skills and competencies (i.e, capability maturity levels, expertise levels, core competencies, etc.)

Application Levels: $1=$ personal $=$ dyadic, $3=$ team, $4=$ dept., $5 .=$ community, $6=$ org., 7. network 
The table represents the following reasoning (along seven KM processes): For the creation of new knowledge, knowledge maps can help in the generation of new concepts by representing emerging topics in cartographic maps, in diagrams, or through visual metaphors (as well as through sketching not included in this classification). While tables could be used in this phase, they might not represent a rich enough structure to uncover new insights or elaborate concepts - they could, however, be used to highlight the possible combination of skills or concepts. To assess the knowledge of experts, groups, or departments, one can employ (as in one example listed in this article) simple tables. Cartographic maps cannot (because of their loose structure) be easily used for ratings. Diagrams, such as matrices, however, can provide visual ratings easily. Visual metaphors, finally, may be too playful and open for the task of rating knowledge assets. To easily identify knowledge, tables usually do not provide a concise overview. Cartographic, diagrammatic or metaphoric maps can provide richer means of overview in this case. In order to develop new knowledge or acquire new knowledge through learning, one can rely on the didactic power of cartographic learning maps (such as trail maps outlining learning steps), diagrams (such as concept maps or mind maps), or metaphoric maps that convey additional insights about the content, or relate what is new to what is already known. This reasoning is equally applicable to knowledge sharing maps, although in this case, tables may provide a simple format to share or communicate the main steps of a method. The use or application of knowledge can be supported by any of the above means: through tables outlining sequential action steps and corresponding documents, concepts or experts, as well as through cartographic trail maps, diagrammatic process maps, or metaphoric depictions (i.e., a ladder or a road) that show how to accomplish a goal, by referencing concepts, documents, or experts. 
For the final knowledge management task examined in this paper, namely knowledge marketing, the attention of the target group is a crucial element. In order to draw the attention of potential clients to an organization's methods, experts, concepts, or skills, novel, original and even surprising ways of representing the offered knowledge need to bee employed. Hence the table format may prove not to be attractive enough. There is, however, a trade-off between map novelty and clarity that has to be managed. ${ }^{1}$

In this way the application parameters for a specific knowledge map can be systematically gathered for a specific application context. The reasoning outlined above may, however, have to be adapted for specific application contexts.

\section{APPLICATION EXAMPLES}

To illustrate key types from these classifications, we provide real-life, interactive online knowledge map examples in this section. In terms of purposes, the examples include knowledge assessment, application, identification, marketing, and acquisition maps. In terms of content, they refer to experts, tools and methods, documents, institutions, concepts, applications, and websites.

The maps range from the departmental to the inter-organizational level. None of the examples are automatically generated maps. As mentioned in (Vail 1999) employing automatic mapping techniques (such as e-mail traffic or questionnaire-based social network analysis software) foregoes the chance of using the collaborative mapping

\footnotetext{
${ }^{1}$ Chillimind (www.chillimind.de), a mobile commerce company, has marketed its skills through an imaginative cartographic map of mobile commerce concepts. Upon first glance, the map seems to depict an island. Only upon close observation can one detect that it's actually a jostle of key technologies, business models, and technical terms from the realm of mobile business. The same holds true for KLM's map for its alliance partners, outlning its partnering strategy.
} 
process itself as a communicative sense-making and identity- or consensus-building process for the involved communities of practice. The knowledge maps that are depicted in Figures 3, 4, and 7 can be viewed and explored interactively at http://www.unisi.ch/knowledgedomainmap.htm.

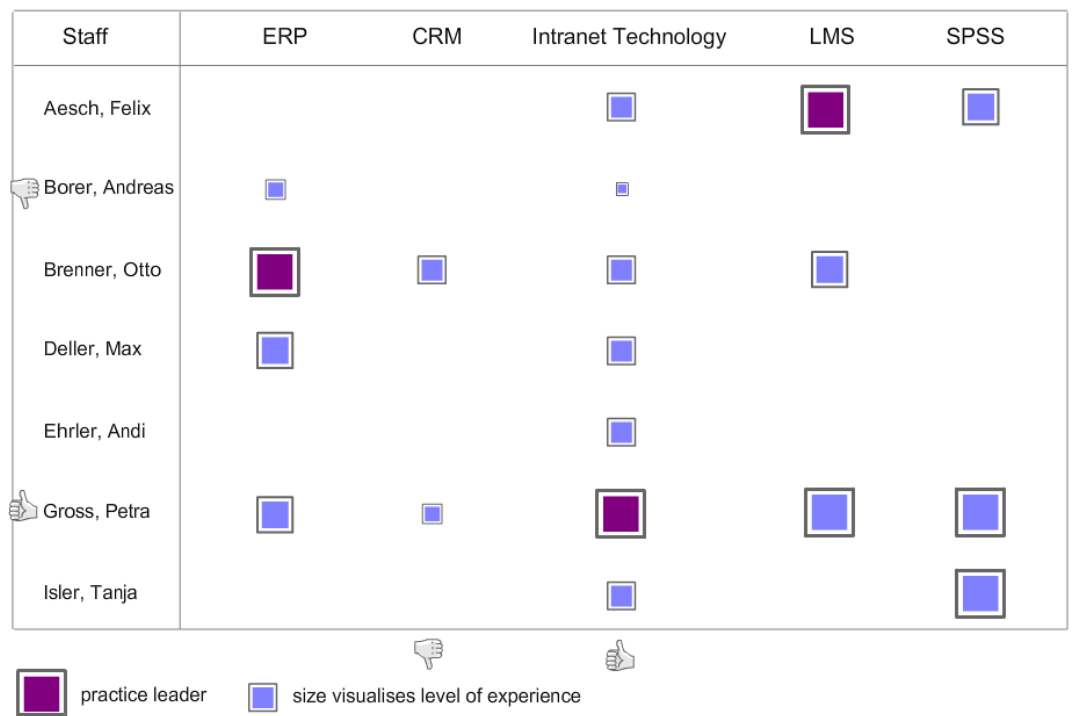

Figure 1: A table-based departmental knowledge assessment map of an IT consultancy

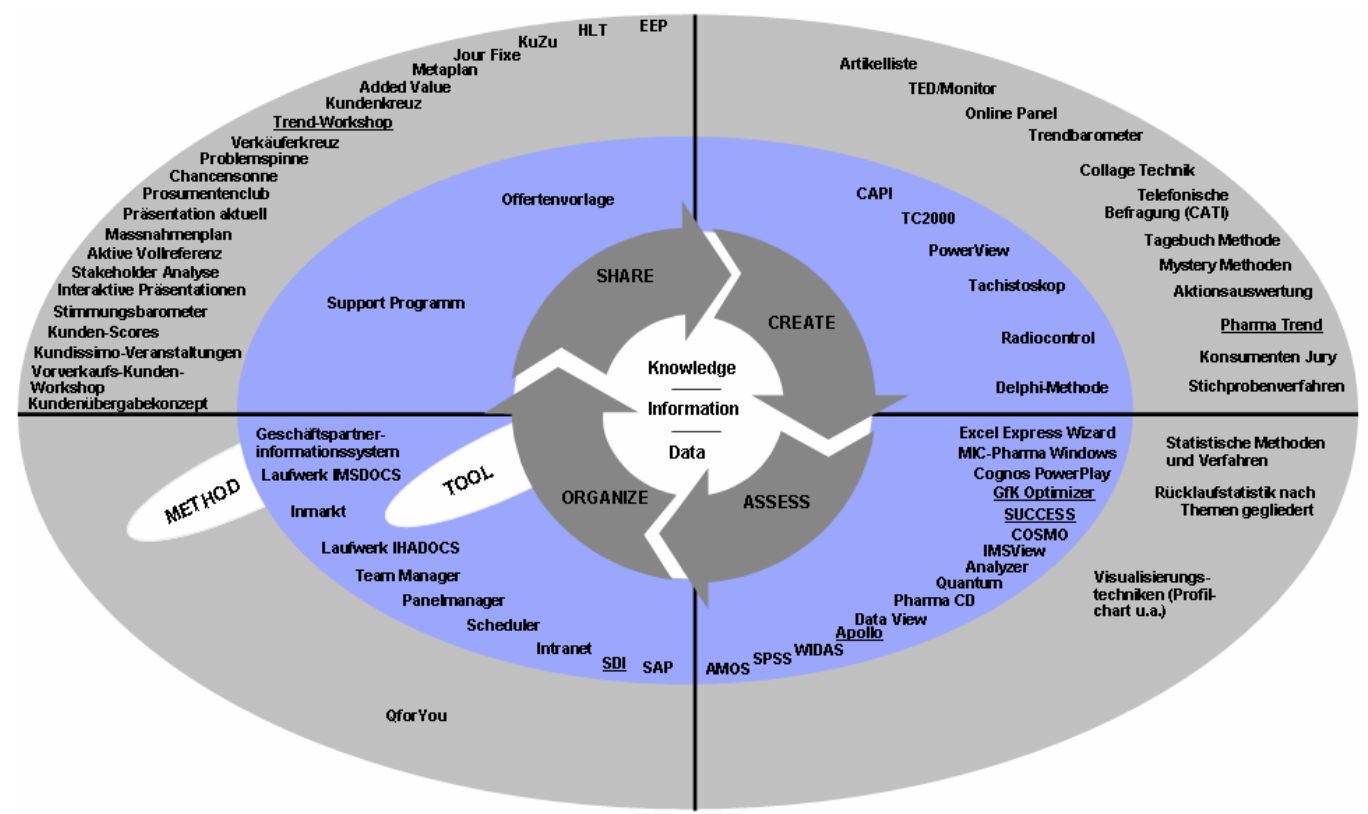

Figure 2: A diagrammatic, knowledge application map of medium-sized market research firm (Eppler 2003) 


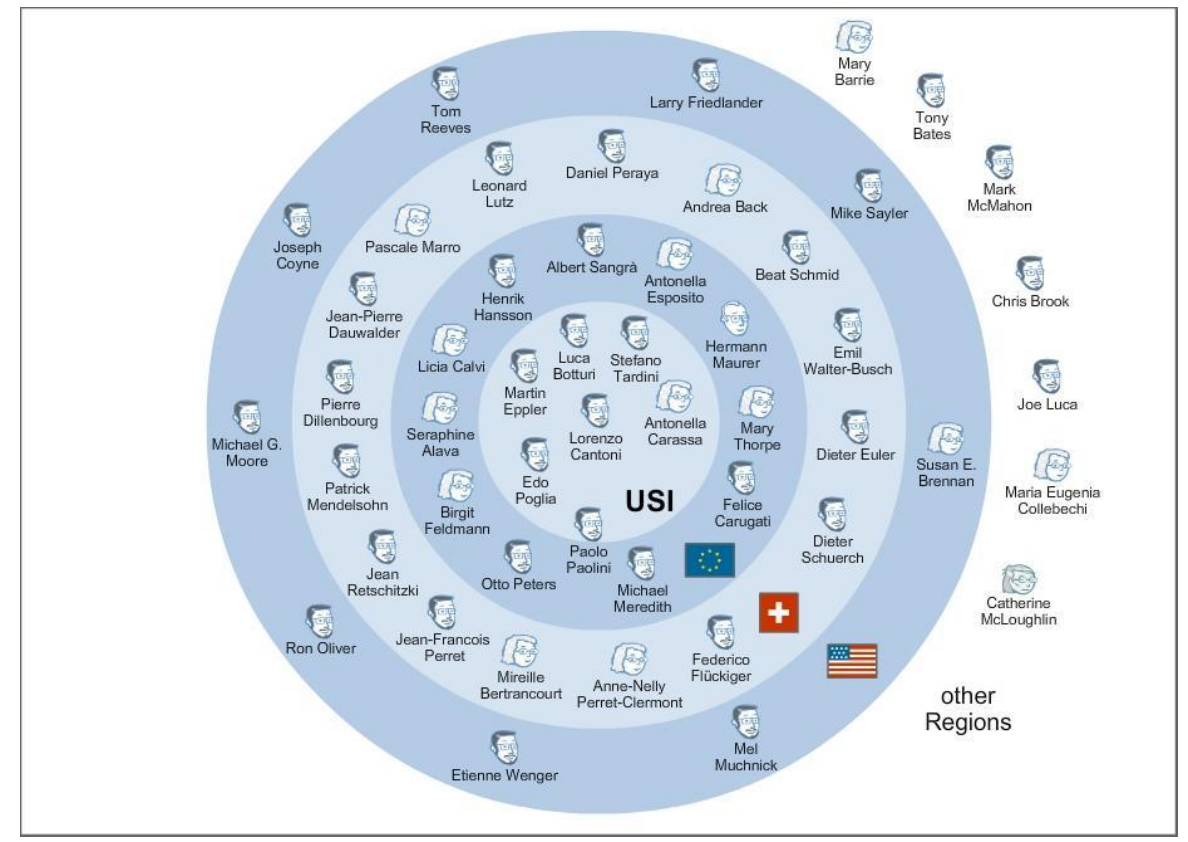

Figure 3: An institution-centred diagrammatic knowledge identification map visualizing researchers in the area of e-learning

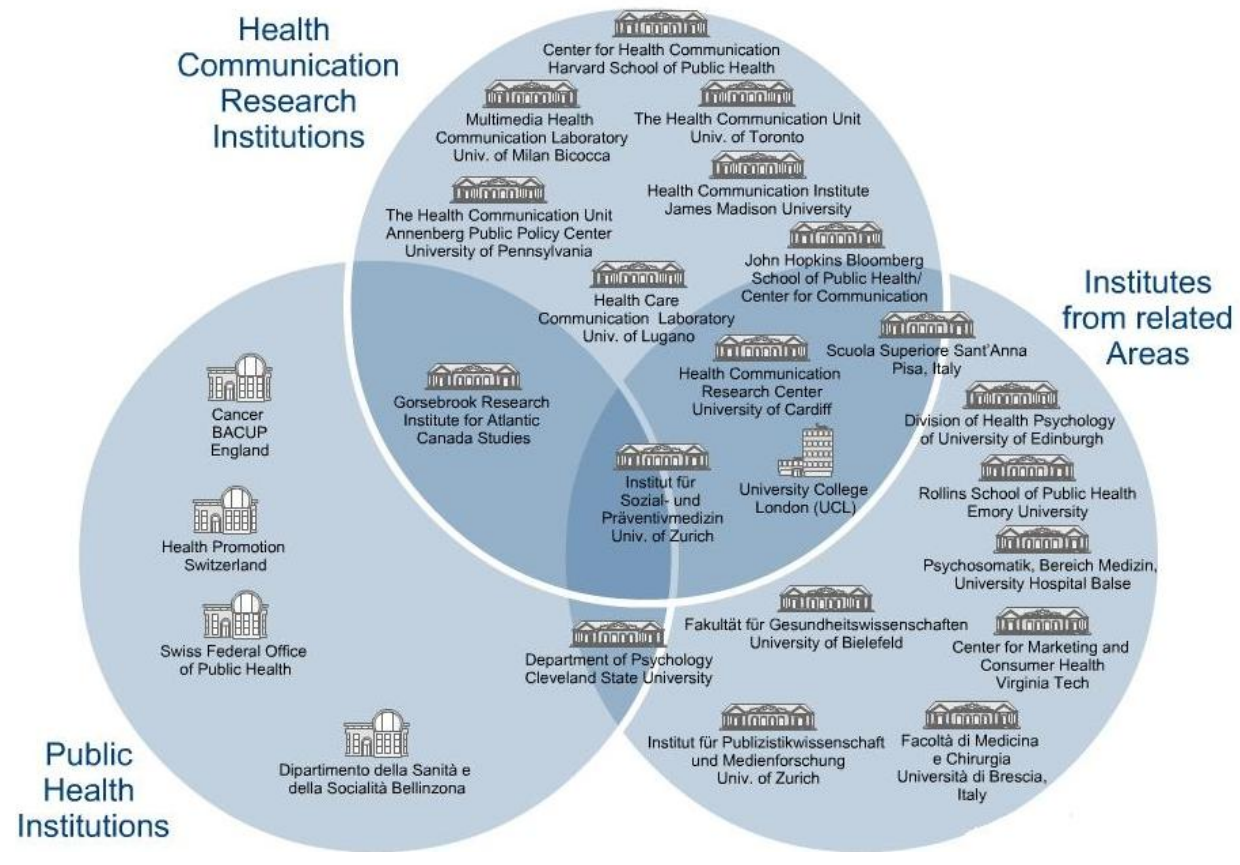

Figure 4: A Venn diagram-based knowledge identification map listing and structuring institutions that have expertise in the area of health communication. 


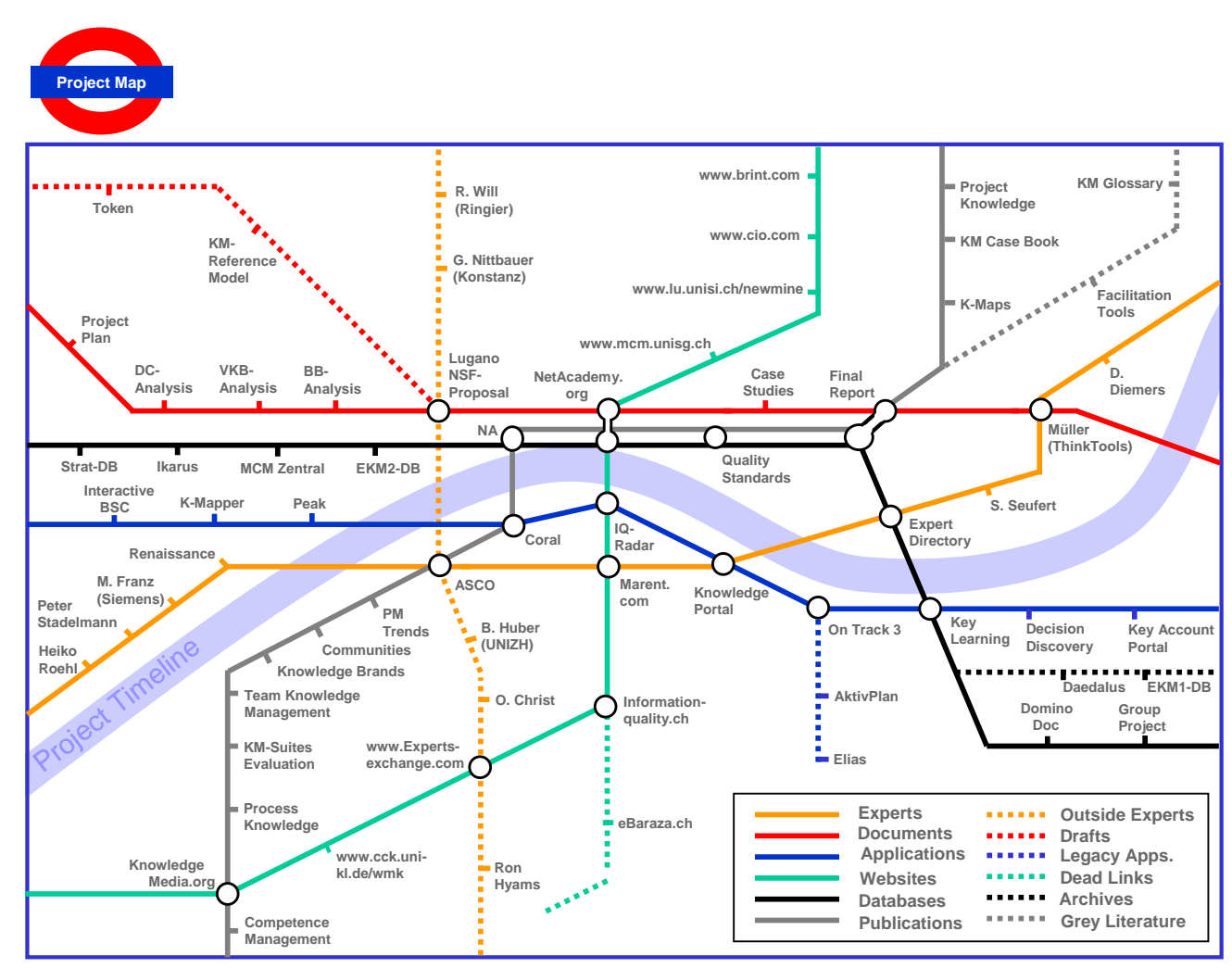

Figure 5: A metro-style knowledge identification map documenting the experiences, experts and documents of a three year project (Eppler, 2003).

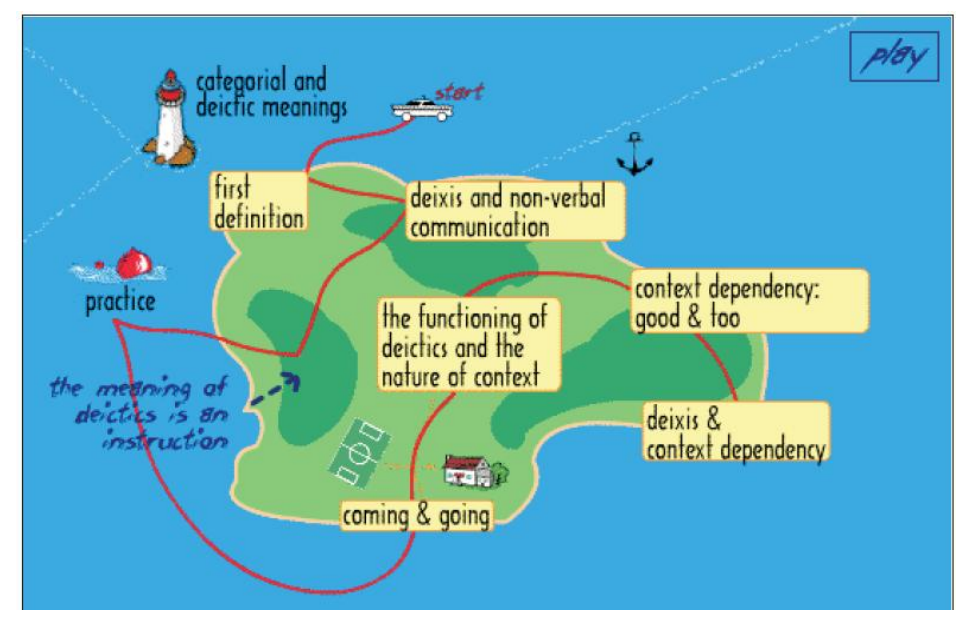

Figure 6: An animated, cartographic knowledge development map (learning path or file rouge map) from the www.swissling.ch project (Armani \& Rocci 2003) 


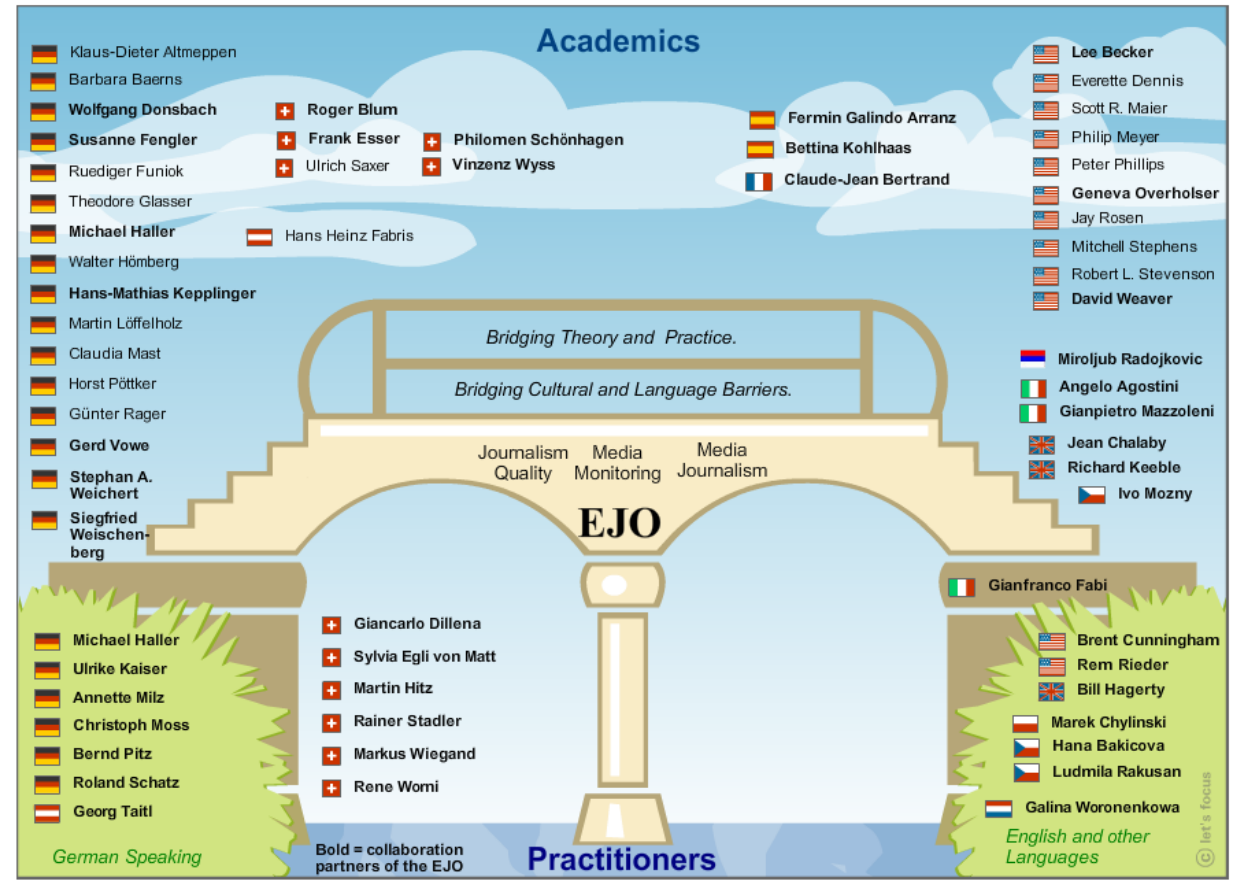

Figure 7: A metaphoric knowledge identification map of a European Research Center $(E J O=$ European Journalism Observatory $)$

The following table compares these seven examples in terms of their main parameters, in order to illustrate the represented spectrum of knowledge maps applied in our projects. 
Table 3: A comparison among the seven maps using the parameters of the classification

\begin{tabular}{|c|c|c|c|c|c|}
\hline KM Process & Map Format & Map Content & Mapping Level & Main Benefits & $\begin{array}{r}\text { Industry } \\
\text { Context }\end{array}$ \\
\hline $\begin{array}{l}\text { 1.Knowledge } \\
\text { Assessment }\end{array}$ & $\begin{array}{l}\text { Table: } \\
\text { domain by } \\
\text { expert }\end{array}$ & Experts & Department & $\begin{array}{l}\text { Training } \\
\text { planning, staff } \\
\text { allocation }\end{array}$ & Telecom \\
\hline $\begin{array}{l}\text { 2. Knowledge } \\
\text { Application } \\
\text { and Knowledge } \\
\text { Marketing }\end{array}$ & $\begin{array}{l}\text { Diagram: } \\
\text { cycle chart }\end{array}$ & Methods & Organization & $\begin{array}{l}\text { Allocation of } \\
\text { methods and } \\
\text { tools along a } \\
\text { business process, } \\
\text { documentation }\end{array}$ & $\begin{array}{l}\text { Market } \\
\text { Research \& } \\
\text { Consulting }\end{array}$ \\
\hline $\begin{array}{l}\text { 3.Knowledge } \\
\text { Identification }\end{array}$ & $\begin{array}{l}\text { Diagram: } \\
\text { concentric } \\
\text { circles }\end{array}$ & Experts & $\begin{array}{l}\text { Inter- } \\
\text { organizational }\end{array}$ & $\begin{array}{l}\text { Highlighting } \\
\text { experts and } \\
\text { contacts }\end{array}$ & $\begin{array}{l}\text { University / } \\
\text { Research \& } \\
\text { Development }\end{array}$ \\
\hline $\begin{array}{l}\text { 4. Knowledge } \\
\text { Identification }\end{array}$ & $\begin{array}{l}\text { Diagram: } \\
\text { Venn } \\
\text { diagram }\end{array}$ & Institutions & $\begin{array}{l}\text { Inter- } \\
\text { organizational }\end{array}$ & $\begin{array}{l}\text { Highlighting } \\
\text { experts and } \\
\text { contacts, } \\
\text { fostering domain } \\
\text { understanding }\end{array}$ & $\begin{array}{l}\text { University / } \\
\text { Research \& } \\
\text { Development }\end{array}$ \\
\hline $\begin{array}{l}\text { 5.Knowledge } \\
\text { identification }\end{array}$ & $\begin{array}{l}\text { Cartographic: } \\
\text { Underground } \\
\text { map }\end{array}$ & $\begin{array}{l}\text { Experts, } \\
\text { documents, } \\
\text { applications, } \\
\text { websites, } \\
\text { databases, } \\
\text { publications }\end{array}$ & $\begin{array}{l}\text { Inter- } \\
\text { organizational }\end{array}$ & $\begin{array}{l}\text { documentation } \\
\text { of knowledge } \\
\text { during a project }\end{array}$ & $\begin{array}{l}\text { Corporate- } \\
\text { University } \\
\text { Collaboration }\end{array}$ \\
\hline $\begin{array}{l}\text { 6. Knowledge } \\
\text { development }\end{array}$ & $\begin{array}{l}\text { Cartographic: } \\
\text { island map }\end{array}$ & $\begin{array}{l}\text { Concepts, } \\
\text { learning } \\
\text { content / } \\
\text { modules }\end{array}$ & $\begin{array}{l}\text { Inter- } \\
\text { organizational }\end{array}$ & $\begin{array}{l}\text { Building } \\
\text { knowledge about } \\
\text { linguistic } \\
\text { theories through } \\
\text { an overview and } \\
\text { sequence }\end{array}$ & $\begin{array}{l}\text { University / } \\
\text { e-learning }\end{array}$ \\
\hline $\begin{array}{l}\text { 7. Knowledge } \\
\text { identification }\end{array}$ & $\begin{array}{l}\text { Metaphor: } \\
\text { bridge }\end{array}$ & Experts & $\begin{array}{l}\text { Inter- } \\
\text { organizational }\end{array}$ & $\begin{array}{l}\text { Identifying } \\
\text { experts and } \\
\text { contacts in a } \\
\text { research domain }\end{array}$ & $\begin{array}{l}\text { University- } \\
\text { Practice } \\
\text { Collaboration }\end{array}$ \\
\hline
\end{tabular}

The table reveals that several of the combinations from the matching table have been implemented, but that there may be many other feasible combinations that are still left to explore and that may provide tangible benefits for current and future knowledge management challenges. Some of these challenges are discussed in the following conclusion. 


\section{CONCLUSION AND LIMITATIONS}

\section{Sapientis est ordinare. It is the function of the wise man to order.}

ARISTOTLE

In this paper, we have made first steps towards a pragmatic - that is to say consistent and useful - taxonomy of knowledge maps that can be used in devising knowledge management solutions. Our approach has been based on rules and guidelines of high quality classifications. As a main contribution, we have shown various ways in which knowledge maps can be classified. The benefit of such multiple classification principles lies in sensitizing managers and researchers for the application parameters and requirements of different knowledge maps formats. We have proposed a tentative matching table that suggests how different map formats can be used for different purposes and contents. The lack of empirical validation of this matching is a weakness of this paper, although the template was presented as a generic starting point for application discussions, rather than a final result. Subsequent research should nevertheless demonstrate through evaluation studies whether this matching is indeed correct and under what circumstances.

A further open research question regards the development of prototypes for some of the stipulated map types in different industry settings, including follow-up evaluations. Related to this question is another research endeavour, namely to match knowledge map types with adequate information technology applications. ${ }^{2}$ A final open research route

\footnotetext{
${ }^{2}$ So far, we have used the following IT applications to manually create (which implies maintainability issues) online interactive knowledge maps: www.lets-focus.com, www.inspiration.com, www.visio.com,
} 
in this rich domain of inquiry concerns trade-offs among map types present in the classification: While some knowledge map formats (such as manually developed metaphoric expert identification maps or diagrammatic knowledge structure maps) may be useful for communication purposes, they may not be highly scaleable or easily maintainable. Identifying and analyzing such application trade-offs in knowledge map types seems like a highly relevant future research area. In conclusion it thus seems that we have only begun to chart this intriguing research territory in the knowledge management domain.

www.mindmanager.com. There are, however, also tools available that can automatically generate knowledge maps, such as the solutions of Aurigin, Autonomy or Semio, to name but three suppliers. 


\section{REFERENCES}

Armani J, Rocci A. 2003. Conceptual maps in e-learning. How map based interfaces help the contextualization of information and the structuring of knowledge. Information Design Journal + Document Design 11(2/3): 171-184.

Bailey KD. 1994. Typologies and Taxonomies: An Introduction to Classification Techniques; Thousand Oakes: Sage.

Bertin J. 1973. Sémiologie Graphique. Paris : Mouton.

Blackwell AF, Engelhardt Y. 2002. A meta taxonomy for diagram research, In Diagrammatic Representation and Reasoning, Anderson, M., Meyer, B., Olivier, P. (eds.); Berlin: Springer.

Bowker G, Star SL. 1999. Sorting Things Out: Classification and its Consequences. Cambridge: MIT Press.

Browne GJ, Ramesh V. 2002. Improving information requirements determination: a cognitive perspective. Information \& Management, 39: 625-645.

Browne GJ, Curley SP, Benson P.G. 1997. Evoking Information in Probability Assessment: Knowledge Maps and Reasoning-based directed Questions. Management Science, 43(1): 1-13.

Burkhard R, Meier M. 2005. Tube Map Visualization: Evaluation of a Novel Knowledge Visualization Application for the Transfer of Knowledge in Long-Term Projects. Journal of Universal Computer Science, 11(4): 473-494.

Burnett S, Illingworth L, Webster L. 2004 Knowledge Auditing and Mapping: A Pragmatic Approach. Knowledge and Process Management, 11 (1):25-37. 
Chi, EH. 2000. A Taxonomy of Visualization Techniques using the Data State Reference Model, Proc. of the IEEE Symposium on Information Visualization: 69-75.

Coyne R. 1995 Designing Information Technology in the Postmodern Age, From Method to Metaphor; Cambridge: MIT Press.

Dherbey GR. Connaissance des choses naturelles et des affaires humaines chez Aristotle. In La Connaissance des Choses, Samana, G. (ed.); Paris : Ellipses: 55-70.

Eppler M. 2002. Making Knowledge Visible through Knowledge Maps, In: Handbook on Knowledge Management, Holsapple, C.W. (ed.); Springer, 2002, 189-206.

Eppler M., Sukowksi O. Managing Team Knowledge: Core Processes, Tools and Enabling Factors. European Management Journal, June: 334-341.

Eppler M. 2003. Managing Information Quality: Increasing the Value of Information in knowledge-intensive Products and Processes; Berlin: Springer.

Galloway D., Mapping Work Processes, Milwaukee: ASQC Quality Press, 1994.

Gordon JL. 2000. Creating Knowledge Maps by Exploiting Dependent Relationships. Knowledge-Based Systems 13: 71-79.

Hellstrom T, Husted K. 2004. Mapping knowledge and intellectual capital in academic environments: A focus group study, Journal of Intellectual Capital 5(1):165-180.

Heng MSH. 2001. Mapping intellectual capital in a small manufacturing enterprise. Journal of Intellectual Capital, 2 (1): 53-60.

Horn RE. 1999. Visual Language; Lexington: MacroVue.

Hodgkinson GP, Maule A.J., Bown NJ. 2004. Causal Cognitive Mapping in the Organizational Strategy Field: A Comparison of Alternative Elicitation Procedures. Organizational Research Methods, 7(1): 3-26. 
Huff A. 1990 (ed.) Mapping Strategic Thought, New York: Wiley.

Huff A, Jenkins M. 2002 (eds.) Mapping Strategic Knowledge; London: Sage Publications.

Kohonen T. 2001. Self-Organizing Maps; New York: Springer.

Lakoff G. 1987. Women, Fire, and Dangerous Things. What Categories Reveal about the Mind; Chicago: University of Chicago Press.

Lohse G, Biolsi K, Walker N, Rueter H. 1994. A classification of visual representations. Communications of the ACM Dec: 36-49.

Meyer AD. 1991. Visual Data in Organizational Research. Organization Science 2(2): $218-236$

Minto B. 1995. The Pyramid Principle, Logic in Writing and Thinking; London: Pitman Publishing.

Newbern D, Dansereau FD. 1995. Knowledge Maps for Knowledge Management, In, Knowledge Management Methods: Practical Approaches to Managing Knowledge, K. Wiig (ed.); Arlington: Schema Press.

Novins P. 1997 Knowledge Representation, Presentation held at MKO Semi-Annual Conference, September 8 .

Peterson MP. 1995 Interactive and Animated Cartography; New Jersey: Prentice Hall. Rankin RA. 1990. A taxonomy of graph types. Information Design Journal 6(2): 147159.

Renukappa SH, Egbu CO. (2004) Knowledge Mapping: Concepts and Benefits for a Sustainable Urban Environment. Proceedings of the 20th Annual Conference 
Association of Researchers in Construction Management (ARCOM) 2004, September 1-3, Farzad Khosrowshahi, University of Herriot-Watt, Edinburgh, UK. Pp 905 - 914.

Shneiderman B. 1996. The eyes have it: A task by data type taxonomy for information visualizations, Proceedings of 1996 IEEE Visual Languages, Los Alamos, CA, IEEE: 336-343.

Smelcer JB, Carmel E. 1997. The effectiveness of different representations for managerial problem solving: Comparing Tables and Maps, Decision Sciences 28(2): $391-420$.

Sparrow J. 1998. The Role of Physical Representations in Knowledge Elicitation. In Knowledge in Organizations, Sparrow, J. (ed.); Thousand Oaks: Sage; 51-78.

Tergan SO, Keller T. (eds) 2005. Knowledge and Information Visualization; Berlin: Springer.

Tory M., Möller T. 2002. A Model-Based Visualization Taxonomy, Working Paper, School of Computing Science, Simon Fraser University.

Tufte. ER. 1990. Envisioning Information; Cheshire: Graphics Press.

Vail EF. 1999. Mapping Organizational Knowledge, Knowledge Management Review Issue 8, May/June: 10-15.

Wexler M. 2001. The who, what, why of knowledge mapping. Journal of Knowledge Management 5(3): 249-263.

Wurman RS. 2001. Information Anxiety 2; Indiana: Macmillan Publishing. 